05

\title{
Структурно-фазовое состояние металла рельса с внутренней трещиной после длительной эксплуатации
}

\author{
(C) С.А. Атрошенко, ${ }^{1,3}$ С.С. Майер, ${ }^{2}$ В.И. Смирнов ${ }^{2}$ \\ ${ }^{1}$ Институт проблем машиноведения РАН, \\ 199178 Санкт-Петербург, Россия \\ ${ }^{2}$ Петербургский государственный университет путей сообщения Императора Александра I, \\ 190031 Санкт-Петербург, Россия \\ ${ }^{3}$ Санкт-Петербургский государственный университет, \\ 199034 Санкт-Петербург, Россия \\ e-mail: satroshe@mail.ru
}

Поступило в Редакцию 19 марта 2021 г.

В окончательной редакции 10 апреля 2021 г.

Принято к публикации 14 апреля 2021 г.

В процессе эксплуатации при циклическом силовом воздействии в металле рельсов со временем происходят различные физико-механические процессы: пластическая деформация поверхности катания, образование внутренних и поверхностных трещин, изменение остаточных напряжений и др. Как следствие, ухудшаются механические характеристики и снижается работоспособность рельсов. Выполнен микроструктурный анализ поверхности сечения двух рельсов с внутренними трещинами - продольной и поперечной. Рельсовые пробы изъяты из эксплуатации после многолетнего срока службы. Фрактографический анализ поверхности трещины и окружающего ее материала указывает на значительную деградацию физико-механических свойств рельсовой стали и интенсивное структурообразование в процессе длительной эксплуатации рельсов.

Ключевые слова: рельсовая сталь, металлография, усталостная трещина, микроструктура металла, поверхность разрушения.

DOI: 10.21883/JTF.2021.09.51215.72-21

\section{Введение}

Результаты полигонных испытаний рельсов с различными физико-механическими свойствами показывают [1-7], что большое влияние на стойкость к образованию контактно-усталостных дефектов оказывает однородная и мелкодисперсная микроструктура. Также большую роль играют такие параметры микроструктуры рельсов, как величина межпластиночного расстояния в перлите, величина перлитных колоний, наличие избыточного феррита [5,7]. Эксплуатационная стойкость металла с более однородной структурой выше и увеличивается с ростом твердости только у рельсов с гомогенной структурой, причем наибольшей конструктивной прочностью рельсов, по мнению различных авторов, обладают рельсы либо при однородной структуре сорбита закалки максимальной дисперсности, либо при однородной структуре отпущенного мартенсита.

Образцы Rail_1, Rail_2 и Rail_3 изучались в работах [8,9]. Исследование структуры образца Rail_1 в области 1 (рис. 1, долом рельса) [9] выявило анизотропию и пористость вблизи поверхности разрушения, а также микротрещины, идущие вглубь материала и вдоль прокатки. Микроструктура - пластинчатый перлит и области динамической рекристаллизации, аналогичные выявленным в [8]. Структура поверхности трещины (область 2 на рис. 1) представлена микротрещинами [9] и полосой с избыточным ферритом в виде ферритной сетки и зерен феррита, что вызывает охрупчивание материала, наблюдаются также отдельные двойники и динамическая рекристаллизация. Появление двойников связано с мартенситным превращением (двойникованным мартенситом), что зависит от скорости термоциклирования и термической предыстории металла [10].

Структура образца Rail_2 в области долома рельса (1 на рис. 1) [9] — волокнисто-деформированный перлит и зоны динамической рекристаллизации, а на поверхности усталостной трещины (2 на рис. 1) сетка микротрещин, пластинчатый перлит и отдельные зерна феррита, иногда - ферритная сетка. Микротрещины в области 3 (рис. 1) идут по границам зерен феррита, выявлены зоны динамической рекристаллизации и большое количество пор, а также глобулярный перлит, появившийся в результате превращения пластинчатого перлита при нагреве стали в процессе работы рельса.

Структура образца Rail_3 в области долома рельса ( 1 на рис. 1) представлена сеткой микротрещин, ферритными зернами, динамической рекристаллизацией наряду с крупными зернами пластинчатого перлита. Микротрещины идут по ферритной сетке и в ферритных зернах. Присутствует также полоса избыточного феррита в виде ферритной сетки. На поверхности усталостной трещины (2 на рис. 1) структура представляет пластинчатый перлит с зонами динамической рекристаллизации, а также двойники. Избыточный феррит представлен в виде 


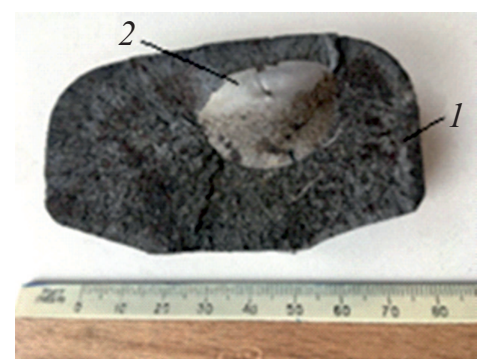

Rail_1

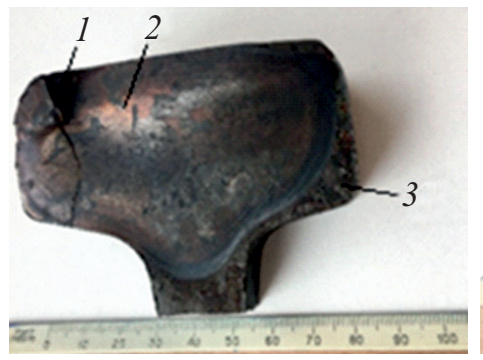

Rail_2

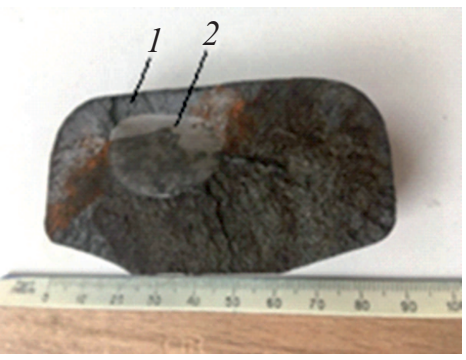

Rail_3

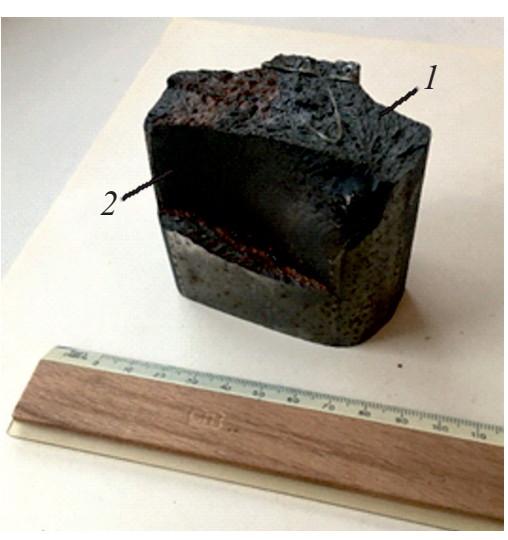

Rail_4

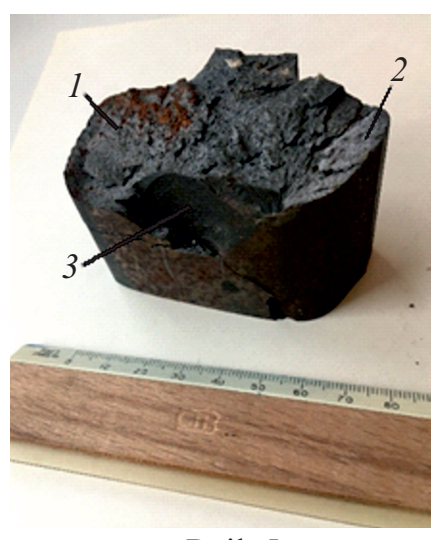

Rail_5

Рис. 1. Общий вид образцов рельсов.

сетки, что способствует охрупчиванию и приводит к разрушению [9].

\section{1. Материал и методика исследования}

Исследования проводились на дифференцированно термоупрочненных железнодорожных рельсах типа Р65 с внутренними поперечной и продольной трещинами. Так как подробное исследование образцов Rail_1, Rail_2 и Rail_3 описано в работах $[8,9]$, то в настоящей работе

Таблица 1. Данные испытаний и приемочные показатели испытанных рельсовых проб

\begin{tabular}{c|c|c|c|c}
\hline Образец & $F, \mathrm{kN}$ & $L, \mathrm{~mm}$ & $F_{\min }, \mathrm{kN}$ & $L_{\min }, \mathrm{mm}$ \\
\hline Rail_1 & 86 & 2.2 & 1750 & 23 \\
\hline Rail_2 & 195 & 5.2 & 1750 & 23 \\
\hline Rail_3 & 540 & 5.4 & 1750 & 23 \\
\hline Rail_4 & 770 & 7.2 & 1750 & 23 \\
\hline Rail_5 & - & - & 1750 & 23
\end{tabular}

Примечание. $F-$ разрушающая нагрузка, $L-$ стрела прогиба, данные после испытаний на статический поперечный изгиб, $F_{\min }, L_{\min }-$ наименьшие (допускаемые) приемочные показатели прочности и жесткости при статическом поперечном изгибе с нагружением на подошву рельса. проводится анализ образцов Rail_4 и Rail_5, а в таблицах для сравнения даны результаты всех пяти образцов. В качестве материала исследования использовали пять

Таблица 2. Доля вязкой составляющей (\%B) в изломе рельсовых сталей

\begin{tabular}{c|c|c}
\hline Материал & Область & $\% \mathrm{~B}$ \\
\hline \multirow{2}{*}{ Rail_1 } & 1 & 97.04 \\
\cline { 2 - 3 } & 2 & 92.18 \\
\cline { 2 - 3 } & переходная & 97.60 \\
\hline \multirow{2}{*}{ Rail_2 } & 1 & 96.18 \\
\cline { 2 - 3 } & 2 & 97.61 \\
\cline { 2 - 3 } & 3 & 92.45 \\
\hline \multirow{5}{*}{ Rail_3 } & 2 & 96.96 \\
\cline { 2 - 3 } & переходная & 92.08 \\
\cline { 2 - 3 } & $1-$ поперек & 96.10 \\
\hline \multirow{2}{*}{ Rail_4 } & $2-$ вдоль & 95.70 \\
\cline { 2 - 3 } & $1-$ поперек & 98.30 \\
\hline & $2-$ поперек & 93.10 \\
\cline { 2 - 3 } & $3-$ вдоль & 96.90
\end{tabular}

Журнал технической фризики, 2021, том 91, вып. 9 
Таблица 3. Количественные характеристики микроструктуры рельсовой стали в различных областях разрушения

\begin{tabular}{|c|c|c|c|c|c|c|c|c|}
\hline Name & Область & $D_{\text {grain }}, \mu \mathrm{m}$ & $h_{\text {perlite }}, d_{p}, \mu \mathrm{m}$ & $L_{t w} x H_{t w}, \mu \mathrm{m}$ & $h_{\text {mart }}, \mu \mathrm{m}$ & $h_{\text {ferrite }}, d_{f}, \mu \mathrm{m}$ & Мартенсит, двойники & Избыток феррита \\
\hline \multirow[t]{2}{*}{ Rail_1 } & 1 & $8-45$ & $h=0.3-1.0$ & - & & - & & \\
\hline & 2 & $4-20$ & $h=0.3-0.6$ & $18.3 \times 0.5$ & & $h=0.8-2.4$ & Мартенсит, двойники & Сетка, зерна \\
\hline \multirow[t]{3}{*}{ Rail_2 } & 1 & $4-12$ & $h=0.3-0.7$ & - & & $h=0.5-1.6$ & & Сетка \\
\hline & 2 & $6-18$ & $h=0.4-1.5$ & - & & $h=0.4-1.8$ & & $\begin{array}{c}\text { Тонкая } \\
\text { сетка, зерна }\end{array}$ \\
\hline & 3 & $3-11$ & $\begin{array}{l}h=3.0-5.0 \\
d=0.8-1.0\end{array}$ & - & & - & & - \\
\hline \multirow[t]{2}{*}{ Rail_3 } & 1 & $11-23$ & $h=0.3-1.6$ & - & & $\begin{array}{c}h=1.5-5.8 \\
d=5.8-14.9\end{array}$ & & $\begin{array}{l}\text { Сетка, } \\
\text { зерна }\end{array}$ \\
\hline & 2 & $7-22$ & $h=0.5-0.8$ & $24.2 \times 0.8$ & & $h=0.6-1.8$ & $\begin{array}{c}\text { Мартенсит, } \\
\text { двойники }\end{array}$ & Сетка \\
\hline \multirow[t]{2}{*}{ Rail_4 } & 1-вдоль & $\begin{array}{c}D_{s f}=5-10 \\
D_{c t}=50-60\end{array}$ & $h=0.1-2.8$ & $66.5 \times 1.0$ & & & Двойники & - \\
\hline & 2-вдоль & $\begin{array}{c}D_{s f}=10-20 \\
D_{c t}=90-100\end{array}$ & $\begin{array}{c}h=7.7-13.3 \\
d=0.7-4.6\end{array}$ & & & & & - \\
\hline \multirow[t]{3}{*}{ Rail_5 } & 1-поперек & $13-101$ & $h-14-33$ & & & $0-100$ & & Обрывки \\
\hline & 2-поперек & $13-101$ & $h=1.4-3.3$ & & & $h=7.0-10.0$ & & сетки \\
\hline & 3-вдоль & $45-121$ & $\begin{array}{l}h=2.8-5.5 \\
d=1.4-4.0\end{array}$ & $71.6 \times 2.5$ & $58-490$ & - & $\begin{array}{c}\text { Полоса } \\
\text { мартенсита, } \\
\text { двойники }\end{array}$ & - \\
\hline
\end{tabular}

Примечание. $D_{\text {grain }}$ - размер зерна, $D_{s f}$ - размер зерна на поверхности у края продольной трещины, $D_{c t}-$ размер зерна в центре, $h_{p e r l i t e}-$ межпластиночное расстояние в перлите, $d_{p}$ - диаметр глобулярного перлита, $L_{t w} x H_{t w}-$ размеры двойников, $h_{m a r t}-$ ширина полосы мартенсита, $h_{\text {ferrite }}$ - толщина ферритной сетки, $d_{f}$ - размер ферритного зерна.

образцов рельсовой стали, свойства и элементный состав которых регламентирует ГОСТ Р 51685-2013. Для анализа разрушения были вырезаны рельсовые пробы длиной 1.1-1.2 m, которые испытывались на статический поперечный изгиб с нагружением на подошву образцов рельса с определением показателей прочности и пластичности на прессе ПМС 320.

Доля вязкой составляющей в изломе стали определялась по ASTME 436-03. Исследование поверхности разрушения проводилось на микроскопе Axio Observer Z1-M в темном поле при увеличении 100, а микроструктура поперечного сечения анализировалась в светлом поле и контрасте C_DIC на том же микроскопе.

\section{2. Результаты и их обсуждение}

Данные испытаний на трехточечный изгиб и наименьшие приемочные показатели испытанных рельсовых проб приведены в табл. 1. Срок службы изъятых из эксплуатации рельсов 18-19 лет. За этот срок рельсы подверглись ориентировочно $(5-50) \cdot 10^{6}$ циклам нагружения, т.е. проходам колеса. Как видно из таблицы, все испытанные рельсовые пробы не удовлетворяют нормативным требованиям прочности и жесткости, что свидетельствует о том, что дефекты обнаружены с большим опозданием.

\section{1. Исследование поверхности разрушения}

Внешний вид поверхности разрушения испытанных образцов представлен на рис. 1, а доля вязкой составляющей на поверхности излома $(\% \mathrm{~B})$ представлена в табл. 2.

Области измерения вязкой составляющей соответствуют указанным на рис. 1: область 2 - поверхность усталостной трещины, области 1,3 - зоны долома для образцов Rail_1, Rail_2 и Rail_3, а для образцов Rail_4 и Rail_5 с продольными трещинами: 2 (Rail_4), 3 (Rail_5) - усталостная трещина, a 1 (Rail_4, Rail_5) и 2 (Rail_5) - зона долома. В табл. 2 также представлено количество волокна в переходной зоне для Rail_1 и Rail_3 образцов.

Как видно из табл. 2, в образцах Rail_1, Rail_3 наблюдается наибольшее уменьшение доли вязкой составляющей на поверхности трещины. Что касается образца Rail_2, то здесь наибольшее уменьшение доли вязкой составляющей происходит на прифронтовой поверхности трещины, затем по мере развития трещины в глубину 


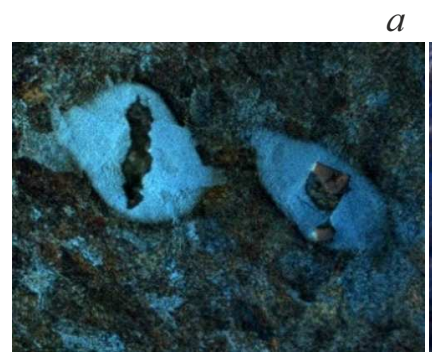

$2 \mu \mathrm{m}$

$a$

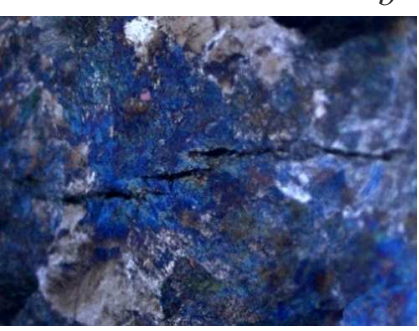

$10 \mu \mathrm{m}$

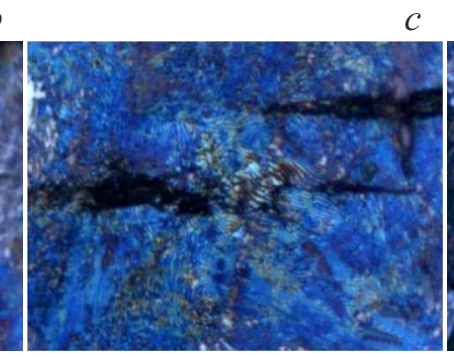

$2 \mu_{1 \rightarrow}$

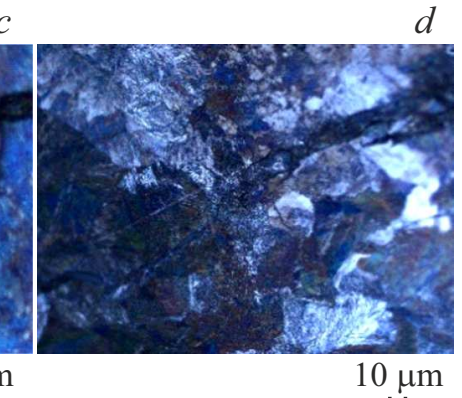

$0 \mu \mathrm{m}$

Рис. 2. Структура области 1 образца Rail_4: $a-\times 1000$ (C_DIC), $b-\times 500, c-\times 2500, d-\times 500$.

$a$

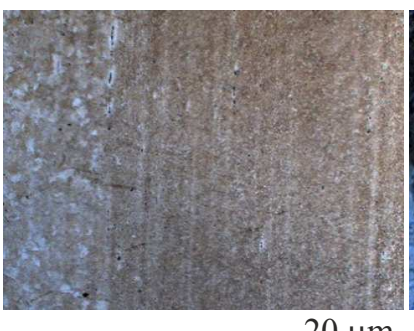

$20 \mu \mathrm{m}$ $b$

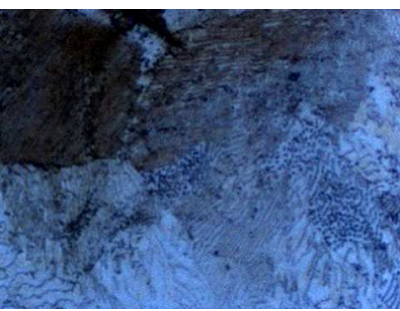

$20 \mu \mathrm{m}$

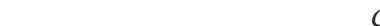

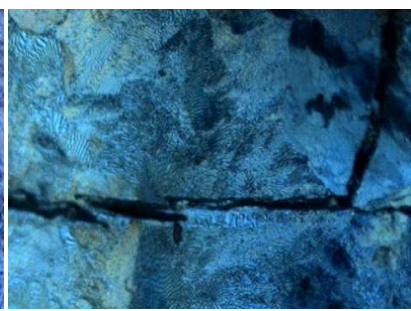

$20 \mu \mathrm{m}$

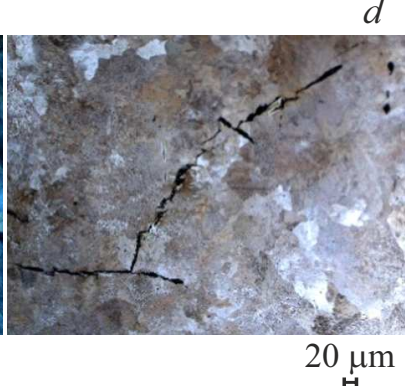

Рис. 3. Структура области 2 образца Rail_4: $a-\times 25, b-\times 2500, c-\times 1000$ (C_DIC), $d-\times 200$.

она повышается. Для образцов Rail_4, Rail_5 наибольшее уменьшение доли вязкой составляющей оказалось в продольной части усталостной трещины (табл. 2).

Такое поведение металла становится более понятным после исследования микроструктуры поперечных шлифов в соответствующих областях разрушения.

\section{2. Исследование микроструктуры поперечных шлифов рельсовых образцов}

Количественная оценка микроструктурных элементов приведена в табл. 3.

\subsubsection{Rail_4}

\section{Область 1}

Структура поверхности образца Rail_4 в области 1 (рис. 1, долом рельса - поперечное разрушение) представлена на рис. 2.

Виден пластинчатый перлит (рис. 2, $b, c$ ) и области динамической рекристаллизации (рис. 2,a). Присутствует разрушение в виде трещин, подобных множественному отколу (рис. 2,b,c), а также двойники (рис. 2,d).

\section{Область 2}

Структура поверхности образца Rail_4 в области 2 (рис. 1, поверхность продольной усталостной трещины) представлена на рис. 3.
B образце Rail_4 от края продольной трещины до основного металла на расстоянии 790-6500 $\mu$ m присутствует наклепанный слой (рис. 3,a), который образовался в процессе циклической пластической деформации, это более мелкозернистая зона с размером зерна $10-20 \mu \mathrm{m}$, в то время как в центре размер зерна составляет 50-110 $\mathrm{m}$ (табл. 3). На границе мелкозернистой зоны с основным металлом много микротрещин, идущих вдоль прокатки от неметаллических включений.

На снимках также виден пластинчатый перлит разной дисперсности (рис. 3,b,c) и глобулярный перлит (рис. $3, b)$, который появился в результате превращения пластинчатого перлита при нагреве стали до высокой температуры в процессе работы рельса. Также наблюдается довольно разветвленная микротрещина (рис. $3, d$ ).

\subsubsection{Rail_5}

\section{Области 1 и 2}

Структура поверхности образца Rail_5 в области 1 и 2 (рис. 1, долом рельса - поперечное разрушение) представлена на рис. 4.

Видна разветвленная микротрещина (рис. 4, $a$ ) и области избыточного феррита в виде разорванной сетки (рис. 4,b). Микротрещины в некоторых местах напоминают ступенчатую откольную щель в ударнонагруженной стали (рис. 4,c). 


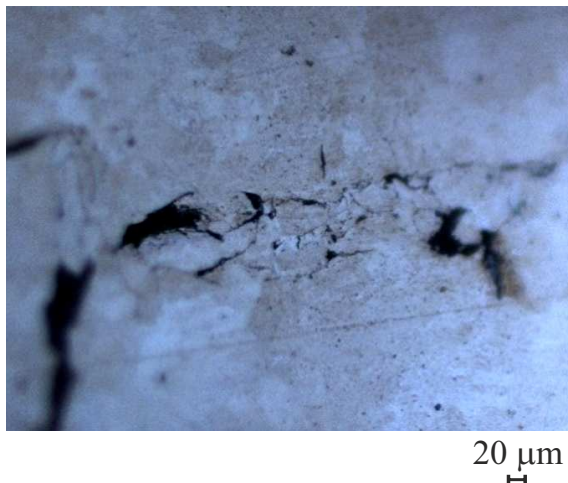

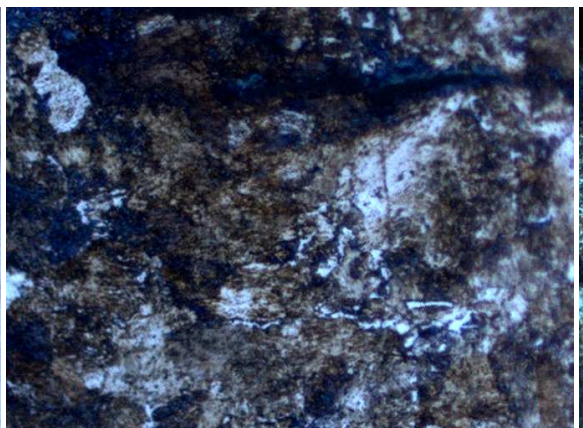

$20 \mu \mathrm{m}$

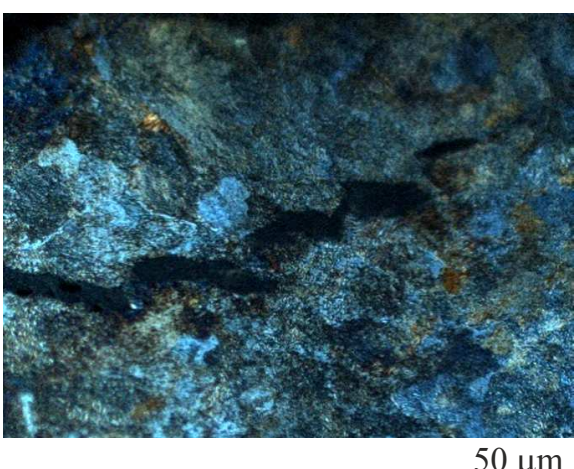

Рис. 4. Структура областей 1 и 2 образца Rail_5: $a-\times 1000, b-\times 1600, c-\times 1000$ (C_DIC).

a

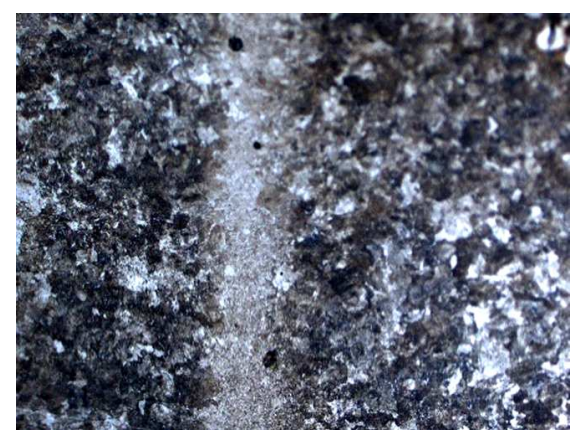

$20 \mu \mathrm{m}$

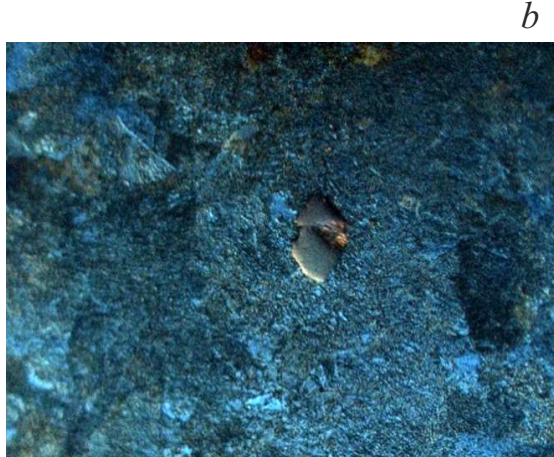

$20 \mu \mathrm{m}$

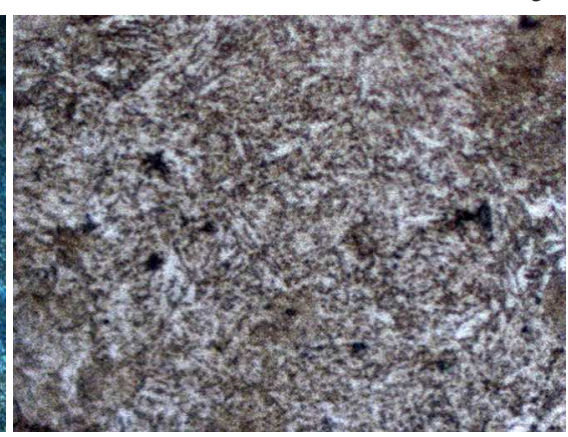

$20 \mu \mathrm{m}$

Pис. 5. Структура области 3 образца Rail_5: $a-\times 200, b-\times 1000$ (C_DIC), $c-\times 2500$.

\section{Область 3}

Структура поверхности образца Rail_5 в области 3 (рис. 1, поверхность продольной усталостной трещины) представлена на рис. 5.

В этой области присутствует довольно широкая полоса мартенсита (табл. 3), расположенная вдоль продольной поверхности разрушения (рис. $5, a, b$ ), в этом районе, вероятно, произошел резкий подьем температуры при эксплуатации рельса и быстрое охлаждение, что вызвало мартенситное превращение в отдельной полосе. Также присутствуют двойники (рис. $5, b$ ), а в области перлита наряду с пластинчатым наблюдается глобулярный перлит (рис. 5,c).

\section{Заключение}

1. Длительная эксплуатация рельсов приводит к интенсивному структурообразованию в результате следующих процессов:

- динамическая рекристаллизация,

- наклеп,

- трещинообразование,

- двойникование,
- мартенситное превращение,

- гомогенизация перлита - переход пластинчатого перлита в глобулярный.

2. Значительное влияние на сопротивление усталостному разрушению оказывает объем феррита в зоне образования трещины: чем оно меньше, тем выше устойчивость к разрушению.

3. На поверхности разрушения исследованных образцов рельсовой стали выделяются области, отличающиеся по доли вязкой составляющей: наибольшее снижение доли вязкой составляющей в образцах Rail_1 и Rail_3 наблюдается на стадии усталостного роста трещины, где наблюдается избыточный феррит в виде разветвленной сетки, которая занимает большую площадь поверхности, а также присутствуют мартенсит и двойники, что способствует снижению пластичности. Образец Rail_2 отличается наибольшим снижением доли вязкой составляющей в приповерхностной области головки рельса, что можно объяснить наличием грубой ферритной сетки с самой большой толщиной, а также самым дисперсным перлитом. Для образцов Rail_4 и Rail_5 наибольшим снижением доли вязкой составляющей оказалось разрушение в продольной части усталостной трещины, хотя оно оказалось меньшим, чем у образцов Rail_1, 
Rail_2 и Rail_3 из-за меньшего количества избыточного феррита.

4. Наиболее высокая разрушающая нагрузка и стрела прогиба наблюдаются у образца Rail_4, что объясняется не только меньшим размером трещины по сравнению с другими пробами, но и наклепом, наличием мартенсита, мелкодисперсного и глобулярного перлита с относительно мелким зерном, а также динамической рекристаллизацией с образованием микрокристаллических зон высокой твердости.

5. Практическая ценность данного исследования состоит в выявлении особенностей структурообразования при работе рельсовых сталей и будет полезна как разработчикам материала, так и специалистам, эксплуатирующим эти материалы.

\section{Конфликт интересов}

Авторы заявляют, что у них нет конфликта интересов.

\section{Список литературы}

[1] Y.D Li., C.B. Liu., N. Xu., X.F. Wu. W.M. Guo, J.B. Shi. Case Studies in Engineering Failure Analysis, 1, 243 (2013). http://dx.doi.org/10.1016/j.csefa.2013.09.003

[2] D.F. Cannon, K.-O. Edel, S.L. Grassie, K. Sawley Fatigue Fracture of Engineering Materials Structures, 26(10), 865 (2003).

[3] L.B. Godefroid, G.L. Faria, L.C. Cândido, T.G. Viana. Engineering Failure Analysis, 58, 407 (2015). http://dx.doi.org/10.1016/j.engfailanal.2015.05.022

[4] Д.К. Нестеров, В.Е. Сапожков, Н.Ф. Левченко, Б.А. Евдокимов, А.И Шевченко. Транспорт: наука, техника, управление, 8, 9 (1991).

[5] Е.В. Полевой, А.Б. Добужская, М.В. Темлянцев. Вестник ПНИПУ, 18 (4), 7 (2016). DOI: $10.15593 / 2224-9877 / 2016.4 .01$

[6] Е.А. Шур, А.И. Борц, А.В. Сухов, А.Ю. Абдурашитов, Л.В. Базанова, К.Л. Заграничек. Вестник ВНИИЖТ, 3, 3 (2015).

[7] Ю.Ф. Иванов, В.Е. Громов, О.А. Перегудов, К.В. Морозов, А.Б. Юрьев. Известия вуз. Черная металлургия, 59 (8), 576 (2016). DOI: 10.17073/0368-0797-2016-8-576-580

[8] С.А. Атрошенко, С.С. Майер, В.И. Смирнов. ФТТ, 62 (10), 1573 (2020). DOI: 10.21883/FTT.2020.10.49898.094 [S.A. Atroshenko, S.S. Mayer, V.I. Smirnov. Physics Solid State, 62 (10), 1741 (2020). DOI: 10.1134/S1063783420100029]

[9] С.А. Атрошенко, С.С. Майер, В.И. Смирнов. ФТТ, 63 (5), 575 (2021). DOI: 10.21883/FTT.2021.05.50803.24

[10] Л.В. Спивак, Н.Е. Щепина. ЖТФ, 90 (7), 1145 (2020). DOI: $10.21883 / J T F .2020 .07 .49449 .381-19$ 